\title{
REAL BEHAVIOUR AND REMAINING LIFETIME OF BRIDGE STRUCTURES
}

The paper presents results of research activities of the Department of Structures and Bridges in the field of investigation of the real behaviour, reliability and durability of existing bridge structures. There are introduced two cases of these research activities in the paper having significant effects on the determining bridge remaining lifetime, which is the basic information from the viewpoint of bridge rehabilitation. The third presented research activity is devoted to the possibility of bridge $R C$ beams strengthening using the FRP lamellas and strips from the viewpoint of determining the resistance of the strengthened $R C$ beams.

\section{Introduction}

At present, the research activities of the Department of Structures and Bridges are oriented on the existing bridge reliability evaluation and investigation of their real behaviour respecting relevant damages of existing bridges and their rehabilitations in form of reconstructions. The main aim of the research is to propose the methodology of determining the bridge remaining lifetime from the viewpoint of ultimate limit states associated with strength and fatigue and to prepare reliability verification concept from the viewpoint of structural durability. To solve the problems, the experimental data related to the analysis of traffic load effects are collected by means of in-situ measurements and numerical simulations of the selected real bridge structures because the correct consideration of the service load effects plays a very important role in the reliability assessment of existing bridges.

Therefore, the fatigue remaining lifetime of the railway bridge stringers was analysed in order to observe and explain the occurrence and development of fatigue cracks of those bridge members caused by significant service load effects. In the case of fatigue life assessment, the service load effects are characterised in the form of stress range spectrum that is necessary to obtain by analysing service load effects.

The corrosion of structural steel is another relevant damage factor significantly influencing the bridge remaining lifetime from the viewpoint of ultimate limit states. In frame of the research activities, the corrosion effect on the buckling resistance and reliability of truss bridge compression chords was observed to determine their remaining lifetime. Because of stochastic character of the corrosion process and its influence on the compression chord reliability, the probabilistic approach was necessary to use respecting random variable input data.
In frame of research activities, the behaviour of the strengthened concrete beams with FRP lamellas was observed to determine the effect of strengthening on the beam shear and bending resistance.

\section{Analysis of railway bridge stringer response to traffic load}

The riveted connections of stringer and cross-beams in the case of railway bridges with open bridge decks are typical details prone to fatigue cracks. Webs of stringer and cross-beam are only connected without flange mutual connecting, so that the joint is verified on the shear and normal forces only. Due to connection arrangement, the bending moment is arising and producing normal stresses causing the crack in the form given in Fig. 1.

To determine the detail fatigue lifetime, the stringer response to service load was observed. Actual railway service load effects may be obtained either by experimental measurement or by numerical simulations. Usually, application of the first approach is financially and time demanding, and therefore it is mostly used for verification of accuracy and calibration of computational model for the second approach. Such a combined approach was applied to determine actual service load effects on the steel riveted stringers of the truss railway bridge, which is situated in $\mathrm{km} 309.309$ of the railway track Kosice - Zilina.

The in-situ measurements oriented on collecting the time dependent normal stress response due to train passages were performed. The stresses were obtained by means of strain gauges whose arrangement can be seen in Fig. 2. The strains were measured and converted to stress records depending on time.

\footnotetext{
* Josef Vican, Jozef Gocal, Branislav Melis, Peter Kotes, Patrik Kotula

Department of Structures and Bridges, Faculty of Civil Engineering, University of Zilina, Zilina, Slovakia, E-mail: josef.vican@fstav.uniza.sk
} 

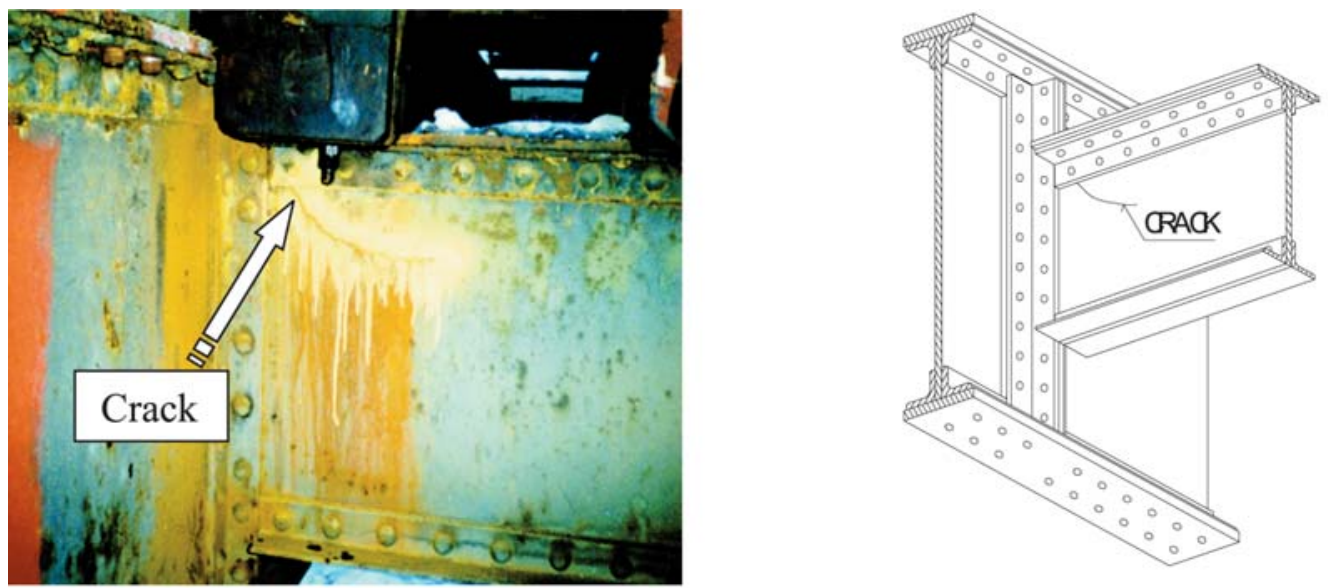

Fig. 1 The example of the observed crack in the stringer web
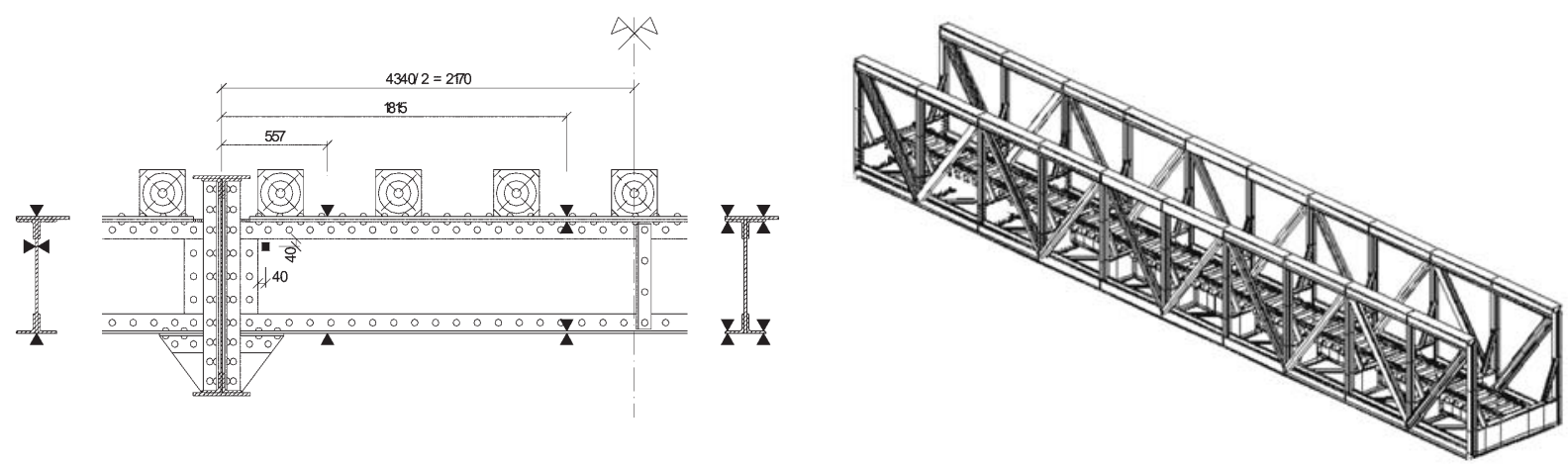

Fig. 2 Strain ganges arrangement of the observed bridge stringer and computational model

of the railway bridge used in numerical simulations

Experimental observation of the stress response was used for verification of a numerical model. Passages of real trains were simulated on the numerical model developed using CAD software NEXIS 3.60 (Fig. 2). Due to time consuming computations, the combined spatial framed - solid numerical model was used.

Verification of the numerical model was realised by comparing normal and shear stresses calculated by means of numerical model and stresses obtained from in-situ measurements on real bridge stringer in monitored places. Regarding to time-consuming computations using spatial numerical model, influence line of stress response in the observed location - the second stringer flange rivet, was developed. It is a very typical location, from where the fatigue crack is starting in case of riveted bridge stringers. To create stress records, the computational algorithm in PASCAL language was developed. The algorithm allows obtaining stress records due to train passages using input influence line and trains data. Complete heavy trains data - their composition, frequency, weight and geometry of wagons were obtained from the ZSR IRIS-N information system. The passenger train passages data were considered according to the actual train schedule.

In accordance with the IRIS-N information system, passages of 163 freight trains and 174 passenger trains were simulated within
Statistical parameters of one-week real traffic

Table 1 and normal traffic according to $\mathrm{EC} 1$

\begin{tabular}{|l|r|r|}
\hline Statistical parameters & Real traffic & $\begin{array}{c}\text { Normal traffic } \\
\text { according to EC1 }\end{array}$ \\
\hline Average value & 17.5648 & 20.3422 \\
\hline Average value fault & 0.0740 & 0.0895 \\
\hline Median & 17.0985 & 21.6000 \\
\hline Modus & 1.2000 & 0.2250 \\
\hline Standard deviation & 14.0017 & 16.6327 \\
\hline Data dispersion & 196.0488 & 276.6454 \\
\hline Kurtosis & -1.1190 & -1.1678 \\
\hline Skewness & 0.2274 & 0.2429 \\
\hline Difference max-min & 68.8439 & 51.6220 \\
\hline Minimum & 0.0001 & 0.0150 \\
\hline Maximum & 68.8440 & 51.6370 \\
\hline Number of values & 35766 & 34552 \\
\hline Reliability level (95.0 \%) & 0.1451 & 0.1754 \\
\hline
\end{tabular}


one-week sample of traffic. The stochastic stress records of simulation of train passages were obtained. From the viewpoint of fatigue assessment, it was necessary to transform stochastic stress record to the stress range spectrum. The classification was realized using the rain-flow method.

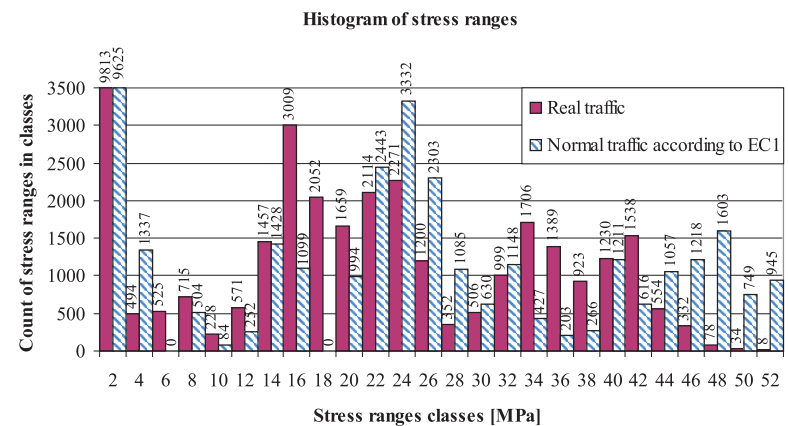

Fig. 3 Histogram of stress ranges of one-week real traffic and normal traffic by ECI

Results obtained from the numerical simulation using IRIS-N were compared with the data calculated for one-week sample of normal traffic according to standard [1] using the same numerical model and calculation approach. Standard [1] introduces twelve types of service trains in all and it also prescribes their sequence in normal traffic (consisting of four types of passenger trains and four types of heavy trains) and heavy traffic (four types of heavy trains).

The comparison of one-week sample of real traffic and normal traffic according to standard [1] is presented in Tab.1 and Fig. 3. It shows that the average value of stress range due to standard normal traffic is about $15.8 \%$ higher than the average value of stress range representing the real traffic. On the other hand, the total number of cycles due to standard normal traffic is about $3.5 \%$ lower than the total number of cycles caused by the passes of the real trains within one week. Results obtained from the numerical

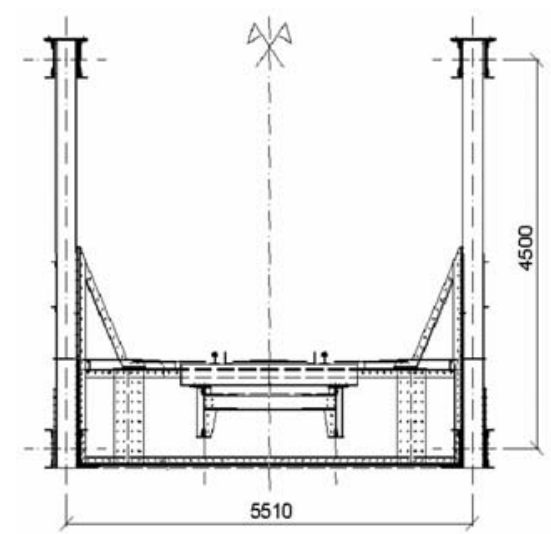

Fig. 4 Cross-section of the observed railway truss bridge and its computational model simulation will be further applied to determine the actual fatigue lifetime of the observed detail.

\section{Resistance of compression chord under corrosion attack}

The lateral stability of upper chords of truss bridge structures of small spans with lower bridge deck is only ensured by the transversal frames consisting of cross beams and stems (Fig. 4). Therefore, investigation of the compression chord buckling resistance is very important because of unstable mode of their failure having harmful consequences from the viewpoint of reliability. To assess their buckling resistance and lifetime a wide variety of degradation phenomena such as corrosion are to be taken into account regarding their ability to decrease substantially the overall reliability and durability of these elements or to mobilize consequently the instability phenomenon. Another aspect is to consider the possible influence of uncertainties in the material properties as well as differences between the theoretical and the actual geometry. All of the above-mentioned factors are stochastic in their nature, so the probabilistic approach to the structural reliability assessment should be required.

In order to solve the proposed task a non-linear finite element prediction of ultimate resistance of the compression chord of railway bridge subjected to corrosion, influenced by a random sample of initial imperfections and material properties were carried out. For the FEM modelling purposes, the existing railway bridge mentioned in chapter 2 having the cross-section according to Fig. 4 was chosen. The stochastic structural model required for probability analysis was created using multipurpose FEM software ANSYS [3] employing combination of BEAM4 for modelling the upper compression chord and BEAM 188 by means of them other bridge components were modelled. Three types of the chord shapes presented in Fig. 5 were analysed in the parametric study. Probabilistic models of the considered random input variables are represented in form of the structural plate thickness having for particular cross-section types of the compression chord Gaussian distribution

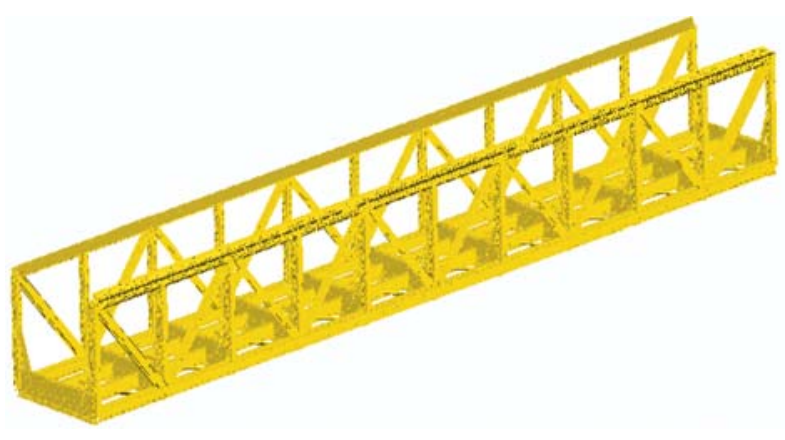




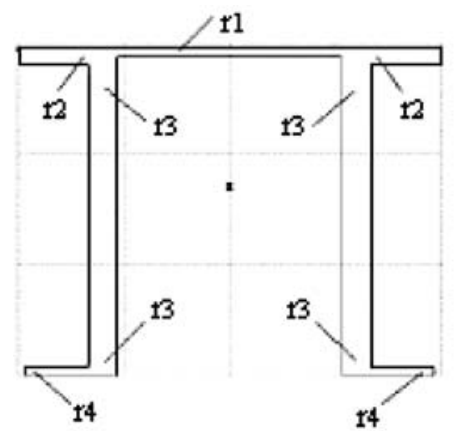

Cross-section No.1

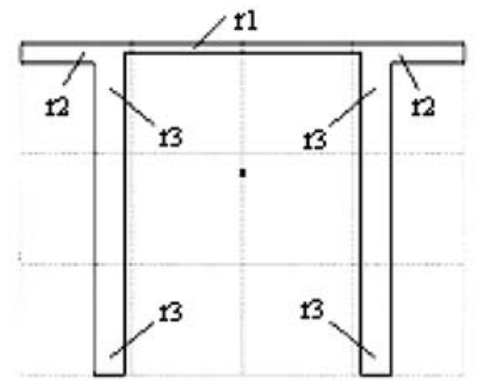

Cross-section No.2

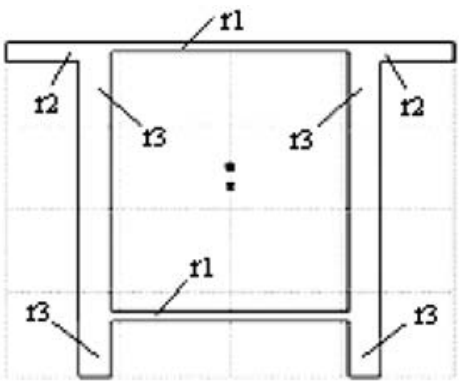

Cross-section No.3

Fig. 5 Various shapes of upper chord cross-section and input parameters of geometry

and randomly varying normally distributed material properties (yield strength and ultimate strength).

The material model involved in the study is a non-linear rate independent Mises plasticity model with bilinear hardening. As a complement to this set of variables, the determination of the initial imperfections shapes was performed in two steps. Firstly, linear buckling analysis was carried out using the Block-Lanczos method for the predefined number of eigenfrequencies. Then, the amplitude of imperfection was calculated according to the standard [2]. Lastly, the shape of the elastic critical buckling mode was used to update the input geometry with an appropriate scaling factor [2], [9]. Then the non-linear analysis using Arc-Length method was applied for simulations of the ultimate strength of compression chord. Simulations of the ultimate resistance were carried out while searching for the limit point using explicit spherical iterations in the probabilistic framework. It involves consecutive repeating of calculations with randomly generated subsets of the input variables and evaluation of response in the form of so-called limit surface. The basic idea of the response-surface method is to approximate the exact ultimate resistance $R(X)$, where $X=\left\{x_{1}, \ldots, x_{n}\right\}$ is the vector of random input variables, by a polynomial function $\hat{R}(x)$ having the following general form

$$
\begin{aligned}
& R(x) \cong \hat{R}(x)=a_{0}+\sum_{i=1}^{N} a_{i} x_{i}+\sum_{i=1}^{N} a_{i i} x_{i}^{2}+ \\
& +\sum_{i=1 j}^{N} \sum_{j=1, j \neq 1}^{N} a_{i j} x_{i} x_{j}
\end{aligned}
$$

Probabilistic models of corrosion damage

\begin{tabular}{|c|c|c|c|}
\hline Author & Mean value & Standard deviation & Distribution \\
\hline Melchers [5] & $0.084 t^{0.826}[\mathrm{~mm}]$ & $0.056 t^{0.826}[\mathrm{~mm}]$ & Normal \\
\hline Frangopol [6] & $32.07 t^{0.5}[\mu \mathrm{m}]$ & $2.89 t^{0.045}[\mu \mathrm{m}]$ & Normal \\
\hline Qin-Cui [7] & $1.67\left[1-\exp (-t / 9.15)^{1.97}\right][\mathrm{mm}]$ & $0.00674\left[1-\exp (-t / 0.0181)^{0.0294}\right][\mathrm{mm}]$ & Normal \\
\hline Guedes Soares [8] & \multicolumn{2}{|c|}{$1.5\left(1-\exp ^{(-t / 10)}\right)[\mathrm{mm}]$} & where $t$ is time in years \\
\hline
\end{tabular}

where the set of coefficients $a=\left\{a_{0}, a_{i}, a_{i i}, a_{i j}\right\}^{T}$, which correspond to the constant, linear, square and cross terms respectively, are to be determined. A limited number of evaluations of the resis-

The investigation of the corrosion effect on the compression chord buckling resistance required to know appropriate corrosion model of structural steel. A lot of effort was exerted to evolve appropriate analytical models of corrosion mainly through extrapolation procedures processing the results of in-situ measurements. This has limited flexibility considering different environmental conditions what is their principal drawback. Current state-of-theart models apply mechanistic or phenomenological approach to modelling corrosive lost of member thickness. However, these models are still of limited applicability. In our case, models presented in Tab. 2 were used. More detailed description of those models is in [4].

A parametric study considering effects of various corrosion models on the time dependent buckling resistance of the compression chord, analysed in form of an approximate function defining the stochastic response on random input variables was carried out. Investigated variants of corrosion influence on 3 types of crosssections (Fig. 5) are shown in Fig. 6 for cross-section No 1. Variants A-D employ all corrosion models acting in different positions on the particular cross-sections, while variants E1-E2 and F1-F2 represent combination of max./min. corrosive effects onto flanges/ webs and interior/exterior parts of the cross-sections mutually. Max/min effects are due to models by Melchers (red colour)/ Frangopol (blue colour). tance function are required to build the surface. 
Results of the time dependent chord buckling resistance for cross-section No. 1 are presented in Fig. 7 and Fig. 8 for corrosion models A - D. The results show the time dependent change of

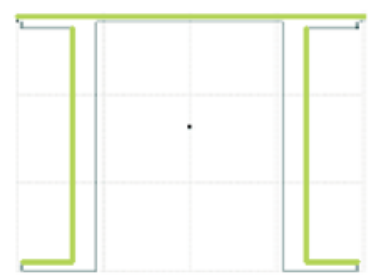

A

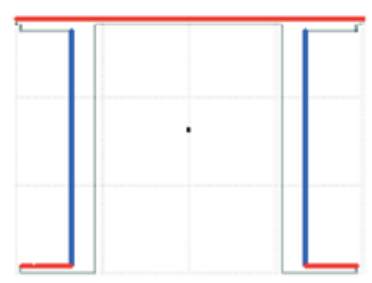

E1

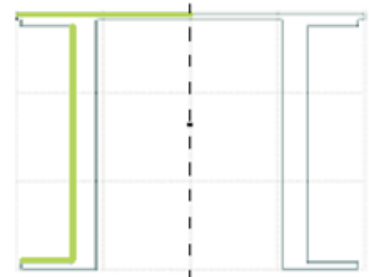

B

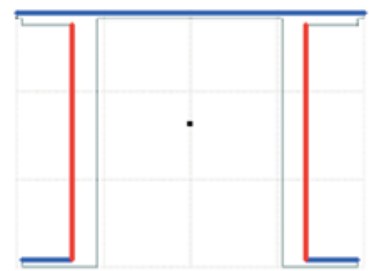

E2 mean value of the chord buckling resistance. However, in other cases of cross-sectional shapes the obtained results showed qualitatively similar tendencies regarding effects of the applied models

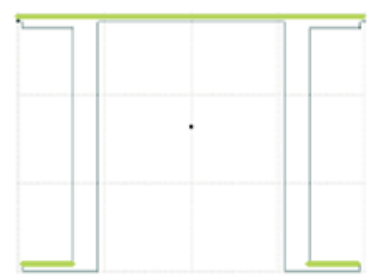

C

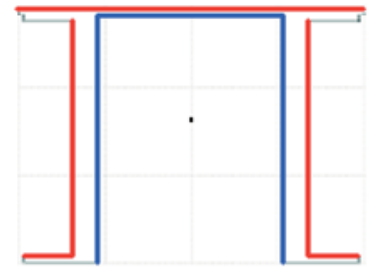

F1

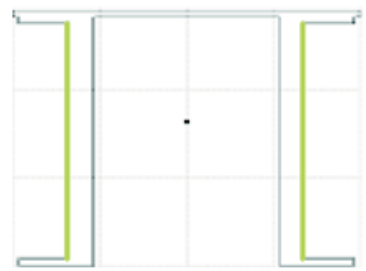

D

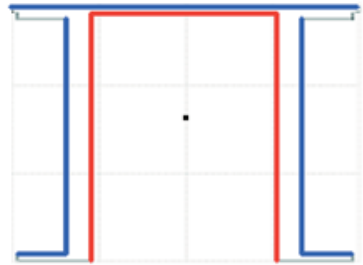

F2

Fig. 6 Various types of corrosion attack of observed chord cross-section No. 1
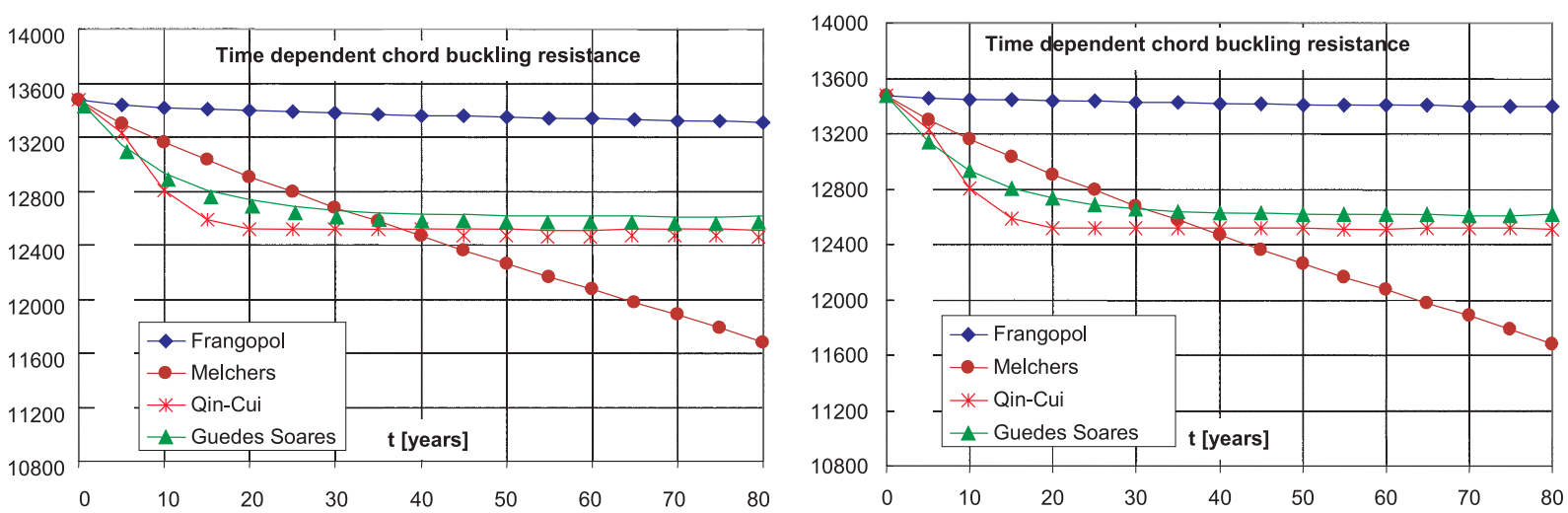

Fig. 7 Time dependent chord buckling resistance for the corrosion model A and B [kN]
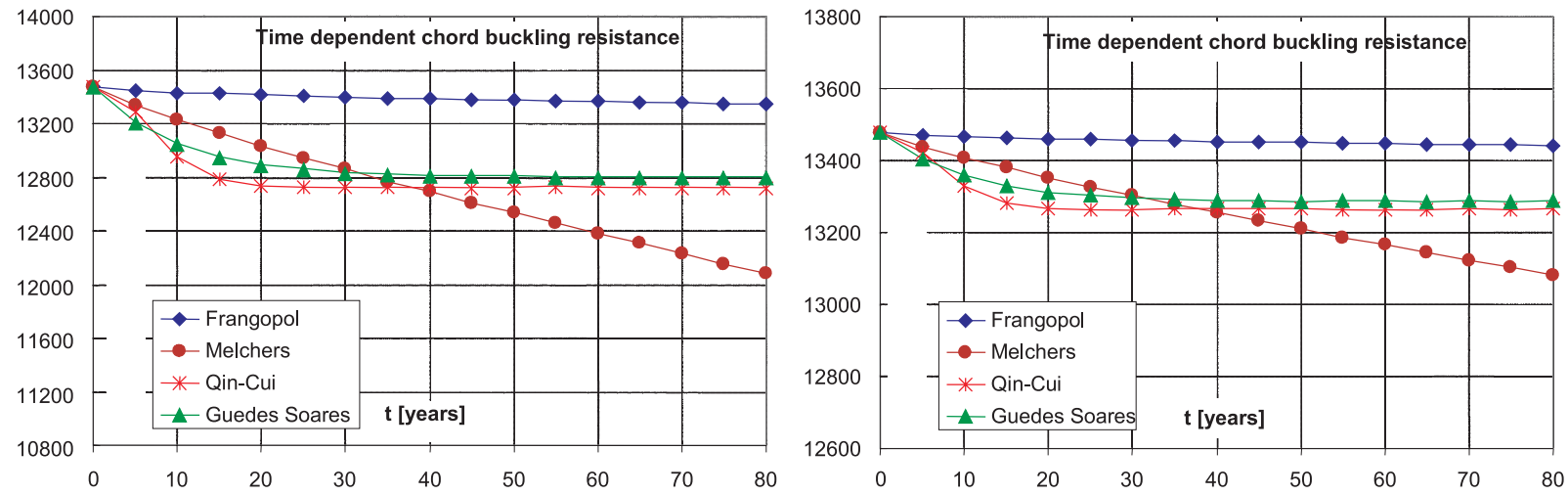

Fig. 8 Time dependent chord buckling resistance for the corrosion model $C$ and $D$ [ $k N$ ]

34 COMMUNICATIONS $2 / 2008$ 

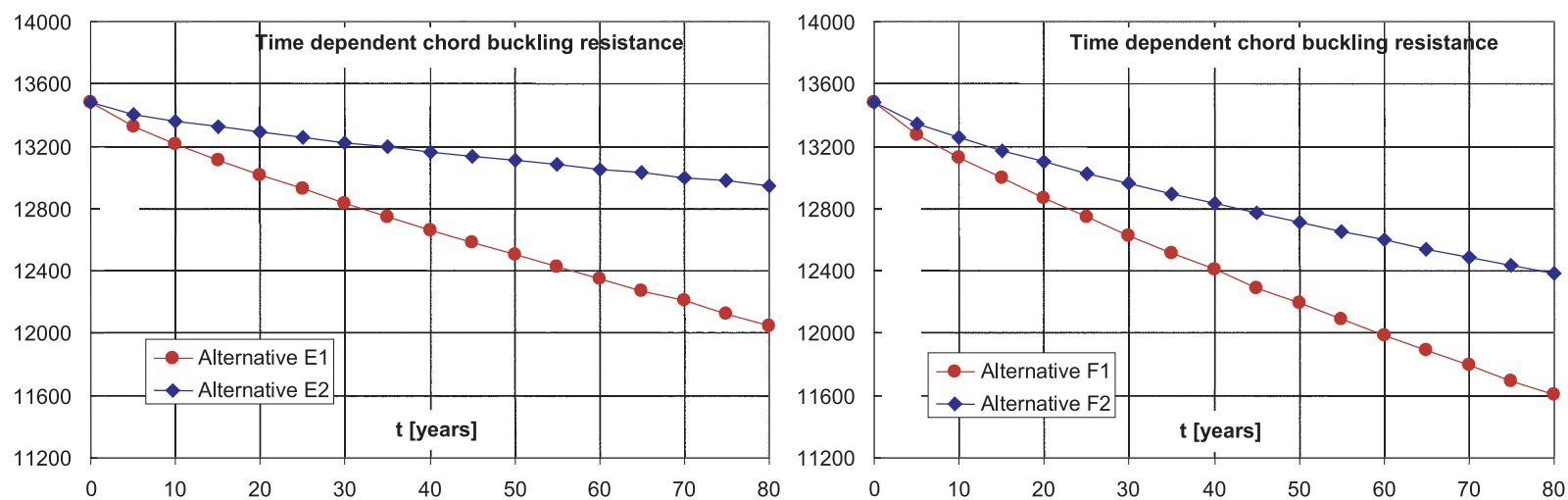

Fig. 9 Time dependent chord buckling resistance for the corrosion model $E$ and $F$ [kN]

of corrosion. Fig. 9 shows the results of the compression chord buckling resistance when combined corrosion models $\mathrm{E}$ and $\mathrm{F}$ according to Fig. 6 are applied. In the case of other investigated cross-sectional shapes presented in Fig. 5, the results were very similar. The results of the parametric study show very similar tendencies of the chord buckling resistance decrease due to various types of corrosion models. The Melchers' model seems to be the most aggressive. On the other hand, the Frangopols' model shows the most favourable results from the viewpoint of chord buckling resistance. Melchers' model also represents the biggest variability of the chord buckling resistance and from the viewpoint aforesaid it seems to be a very conservative and pessimistic model. However, the maximum decrease of mean value of the compression chord buckling resistance due to corrosion attack does not exceed $14 \%$ in any cases. Corrosion models according to Qin-Cui or Guedes Soares could be found as the optimal ones for practical use in our condition.

\section{Experimental research of strenghtened $\mathrm{RC}$ beam resistance}

The Department of Structures and Bridges is also orienting its activities in the field of the experimental and theoretical research
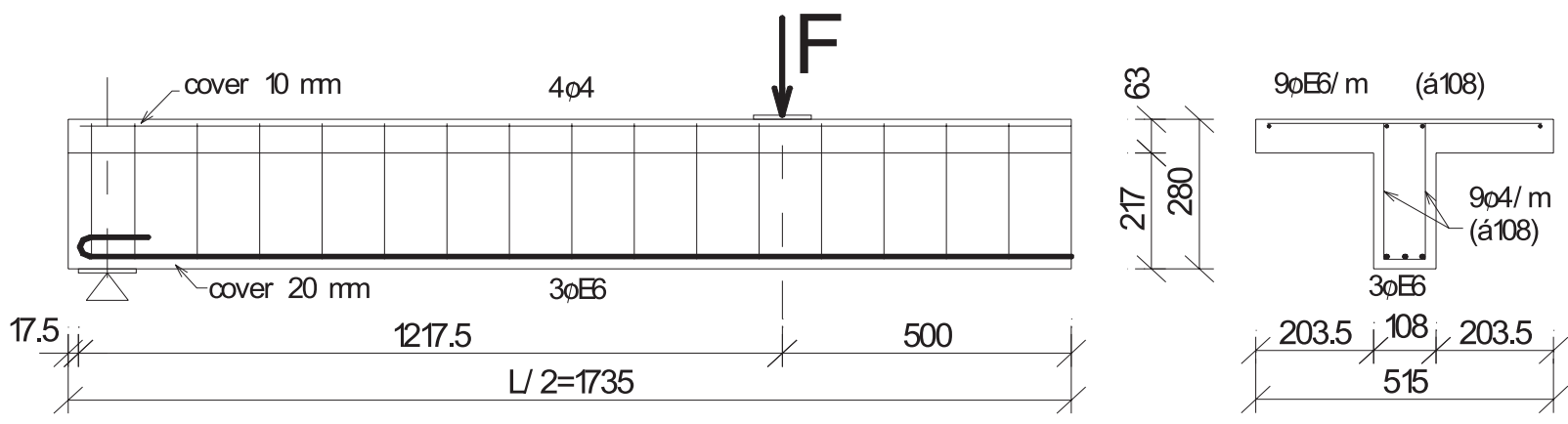

Fig. 10 Characteristics of the tested $R C$ beam TO_0
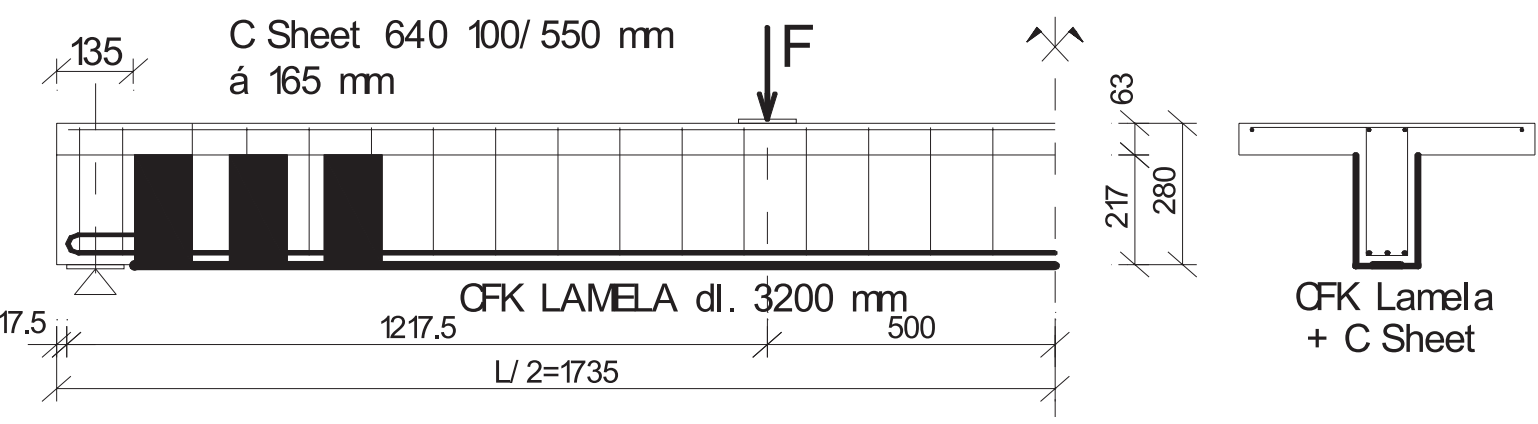

CFK Lamela

+ C Sheet

Fig. 11 Characteristics of the strengthened RC beams 
of the bending and shear resistance of reinforced concrete (RC) beams strengthened by FRP. In the experimental analysis, two types of beam specimens were considered. Firstly, the non-strengthened RC girder TO_0 was made having comparison function. The beam TO_0 shown in Fig. 10 is three times reduced compared to the RC girder of the actually existing bridge located near the village Kolárovice on the road I / 18 . The $1 / 3$ scale beam was considered because of the laboratory possibilities and the real beam geometry. Next, the five strengthened $\mathrm{RC}$ beams TO_1, TO_2, TO_3, TO_4 and TO_5 were fabricated (Fig. 11). The beams were strengthened by one MBrace ${ }^{\circledR}$ S\&P CFK lamella 150/2000 for bending and by three S\&P C-Sheet 640 of width $100 \mathrm{~mm}$ for shear. Three of these girders were statically loaded and two of these girders were dynamically loaded.

Firstly, the non-strengthened beam TO_0 was statically loaded till the failure in order to obtain the maximum force at the failure and to compare it with the maximum one at the failure of the strengthened girders. The dependence of the deflection on the loading force in the middle span is shown in Fig. 12. The maximum failure force was equal to $F_{\max , T O \_0}=30.0 \mathrm{kN}$.

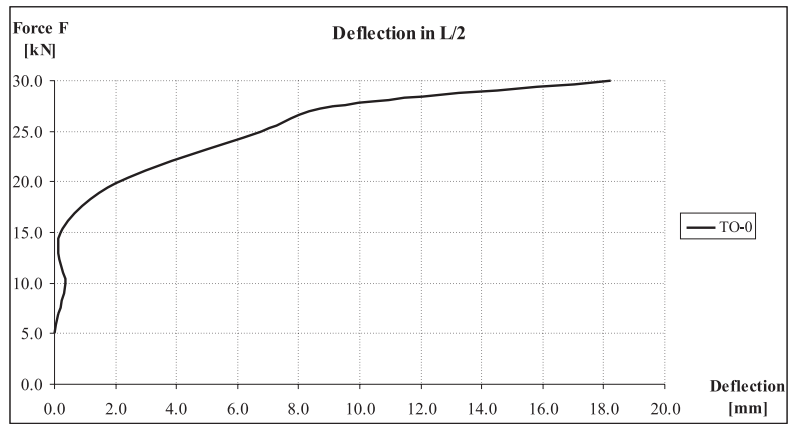

Fig. 12 The beam deflection in dependence on the load force - T-beam TO_0.

Next, three T-beams TO_1, TO_2 and TO_3 were statically tested. The resistance sensors and strain gauges were used to measure deflections and the strains.

The program of the static proof of the RC T-beams series TO consisted of:

1) Prior to testing, the non-strengthened girders TO_1, TO_2, TO_3 were cracked (the partial failure) in the bending area to simulate an overloading conditions which were corresponding to the limited bending crack width $w_{\text {lim }}=0.02 \mathrm{~mm}$.

2) Strengthening the partially cracked RC T-beams TO_1, TO_2 and TO_3 using 1 lamella S\&P CFK 150/2000 50/1.2 mm in the bending area, which was completed in the shear area by C-Sheet 640 strips.

3) Loading tests of the strengthened RC T-beams as far as bending failure.

The value of the maximum force at the T-beams failure after strengthening (step 3) was practically the same for all statically loaded beams, $F_{\max , T O_{1}}=63.0 \mathrm{kN}$. It means the load-carrying capacity increasing about $110 \%$. The degree of the strengthening $\eta$, which is equal to the ratio between the resistance bending moment $M_{R d, f}$ of strengthened cross-section and the resistance bending moment $M_{R d, 0}$ of non-strengthened cross-section, is higher than 2.0. Considering linear dependence between bending moment and load forces, the degree of strengthening may be defined by:

$$
\eta=M_{R d, f} / M_{R d, 0}=F_{\max , T O_{-} 0} / F_{\max , T O_{-} 1}=2.10 \geq 2.0
$$

The degree of strengthening should be less than 2.0. Therefore, the maximum load force, that should be practically used, is equal to $F_{\text {max }, T O_{-} 1}=60.0 \mathrm{kN}$.

Two T-beams TO_4 and TO_5 were dynamically loaded firstly. The deflections and the strains were again measured by means of the resistance sensors and strain gauges. The harmonic loading having frequency $3 \mathrm{~Hz}$ represented the dynamic load with 2 million cycles. In the case of the T-beam TO_4, the minimum force was $2.0 \mathrm{kN}$ and the maximum one was $10.0 \mathrm{kN}$. In the case of the Tbeam TO_5, the minimum force was also $2.0 \mathrm{kN}$, but the maximum one was $14.0 \mathrm{kN}$. This difference between maximum forces was used in order to observe the influence of the various loading on the cracks formation and the cracks development and on the loadcarrying capacity of the T-beams. The maximum and the minimum deformations of the lifting spindle (TO_4) are shown in Fig. 13.
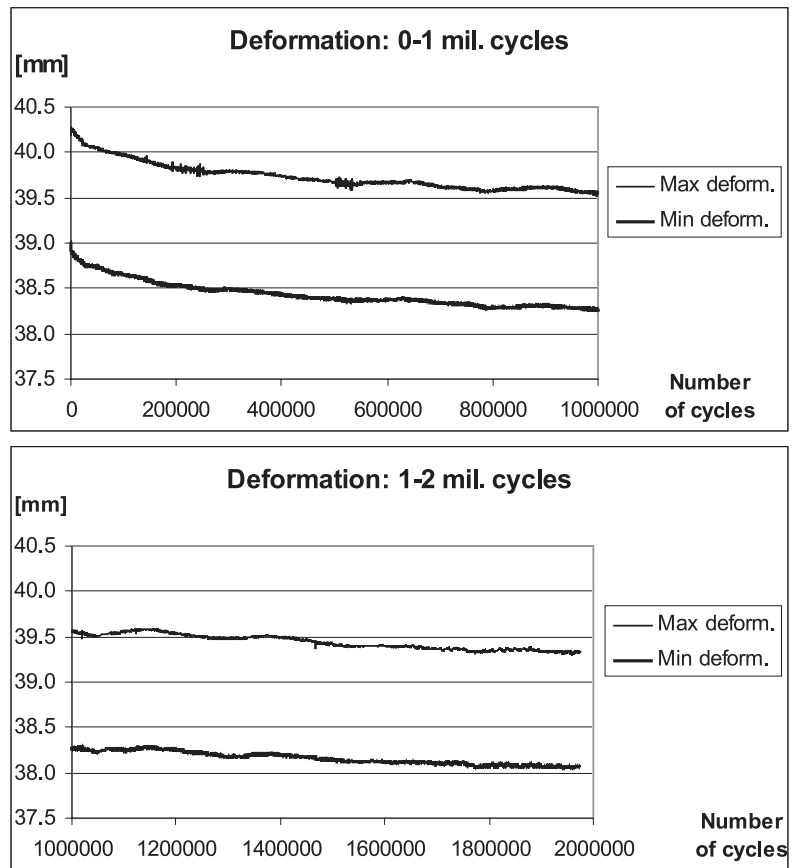

Fig. 13 The maximum and the minimum deformations of the lifting spindle - T-beam TO_4

After dynamic loading, T-beams TO_4 and TO_5 were statically loaded as far as their failure. The new cracks formation and 
the cracks development were again observed. The values of deflection in the middle of the girder $(\mathrm{L} / 2)$ span versus to loading force are shown in Fig. 14. The maximum force at the beam failure is equal to $F_{\max , T O}=53.0 \mathrm{kN}$ in case of girder TO_4 and $F_{\max , T O} 5$ $=55.0 \mathrm{kN}$ in case of the girder TO_5.

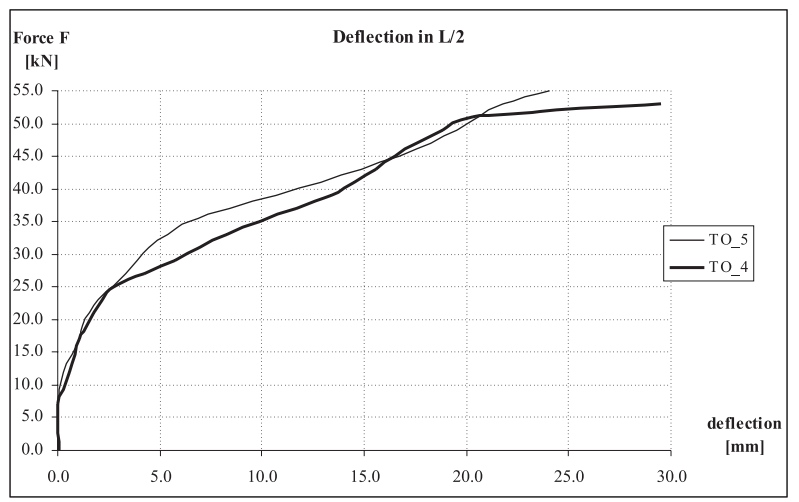

Fig. 14 Deflection of the beam middle spans depending on the load force - T-beam TO_4, TO_5

\section{Conclusion}

In the paper, two cases of the research activities of the Department of Structures and Bridges were presented referring to the investigation of the bridge remaining lifetime determination from the viewpoint of fatigue and corrosion damage. Moreover, the experimental research results are presented related to the behaviour investigation of the bridge RC beams strengthened by means of FRP lamellas and strips from the viewpoint of determining their bending and shear resistance.

\section{Acknowledgement}

The paper presents results of the research activities supported by the Slovak Research and Development Agency under the contract No. APVV-20-010005 and by the Slovak Grant Agency, grant No.1/4201/07.

\section{References}

[1] STN EN 1991-2 Traffic Actions on Bridges, SUTN Bratislava 2005.

[2] STN EN 1993-2 Design of Steel Structures. Part 2: Steel bridges, Bratislava 2007.

[3] REH, S., BELEY, D. J., MUKHERJEE, S., ENG HUI, K., Probabilistic Finite Element Analysis Using ANSYS, Structural Safety, Elsevier, 2006.

[4] VICAN, J., KURCIK, F., Probabilistic Approach to the Ultimate Strength of Compression Chords of Railway Bridges Considering Corrosion, Steel Bridges, Prague, 2006.

[5] MELCHERS, R. E.: Corrosion Uncertainty Modelling for Steel Structures, Journal of Constructional Steel Research, Elsevier, 1999.

[6] AKGUL, F., FRANGOPOL, D. M.: Lifetime Performance Analysis of Existing Steel Girder Bridge Superstructures, Journal of Constructional Steel Research, Elsevier, 2004.

[7] QIN S., CUI W.: Effect of Corrosion Models on the Time-dependent Reliability of Steel Plated Elements, Marine Structures, Elsevier, 2003.

[8] GUEDES SOARES, C., GARBATOV, Y.: Reliability of Maintained, Corrosion Protected Plates Subjected to Non-linear Corrosion and Compressive Loads, Marine Structures, Elsevier, 1999.

[9] KALA Z.: Effect of Steel Member Initial Bow on the Buckling Resistance-stochastic Approach, Proc. of $1^{\text {st }}$ International Scientific Seminar New Trends in Statics and DSynamics of Buildings, Bratislava, 2001. 